\title{
The expiration reflex from the vocal folds
}

\author{
J. Korpas, ${ }^{1}$ J. Jakus ${ }^{2}$ \\ ${ }^{1}$ Department of Pathophysiology and \\ ${ }^{2}$ Department of Biophysics, Jessenius Medical School, Comenius University, Martin, Slovakia
}

Received: June 27, 2000

Accepted: September 12, 2000

\begin{abstract}
The authors present their 30 years' experience with expiration reflex. The reflex can be elicited from vocal folds by mechanical, chemical or electrical stimulation of the superior laryngeal nerve of man and laboratory animals, except mice and rats. It manifests itself by a short, forcible expiratory effort without a preceding inspiration which is indispensable for cough effort. The role of expiration reflex is to prevent penetration of foreign bodies into airways, expelling phlegm and detritus from subglottal area. The initial inspiration before expiration is undesired and could lead to inspiration pneumonia. The reflex is well known to laryngologists as "laryngeal cough." Its receptors are small in number, localised mainly in medial margin of vocal folds deep in mucosa which can explain their stability in pathological conditions of the larygx.

Afferentiation of the reflex is via laryngeal nerve similarly to sneezing and cough. Expiration reflex is not co-ordinated by a single "centre" but rather by a network system in the brain stem. Its motor pattern is supposedly produced by "multifunctional" population of medullar neurones in Bötzinger complex and the rostral ventral respiratory group involved also in the genesis of breathing and cough. However, in cats also other neurones may play a vital role in production, shaping and mediation of the motor pattern of respiratory reflex, localised in rostral pons, lateral tegmental field or in the raphe medullar midline.
\end{abstract}

Keywords: expiration reflex, defensive reflexes of airways, glottal defensive reflex

Our study of mechanoreceptive sensitivity of respiratory mucosa started 20 years ago. Insertion of a thin nylon fibre through a tiny laryngoscopic opening in anaesthetised cats and stimulation of laryngeal mucosa evoked either a fit of cough with initial inspiratory effort or a single expiratory effort without the preceding inspiration (Fig. 1). Such response was surprising since according to Bucher and Jacot (4) initial inspiration is an indispensable prerequisite of cough that follows it, and, without it the

Correspondence should be addressed to

Prof. Juraj Korpas

Department of Pathophysiology, Jessenius Medical School

03753 Martin, P.O. Box 34, Slovakia 
cough expiration is unthinkable. We paid particular attention to this observation and revised its validity. We found that using the Bucher's and Jacot's method an intensive mechanical stimulation of laryngeal mucosa can elicit cough expiration even when inspiration is blocked (17).
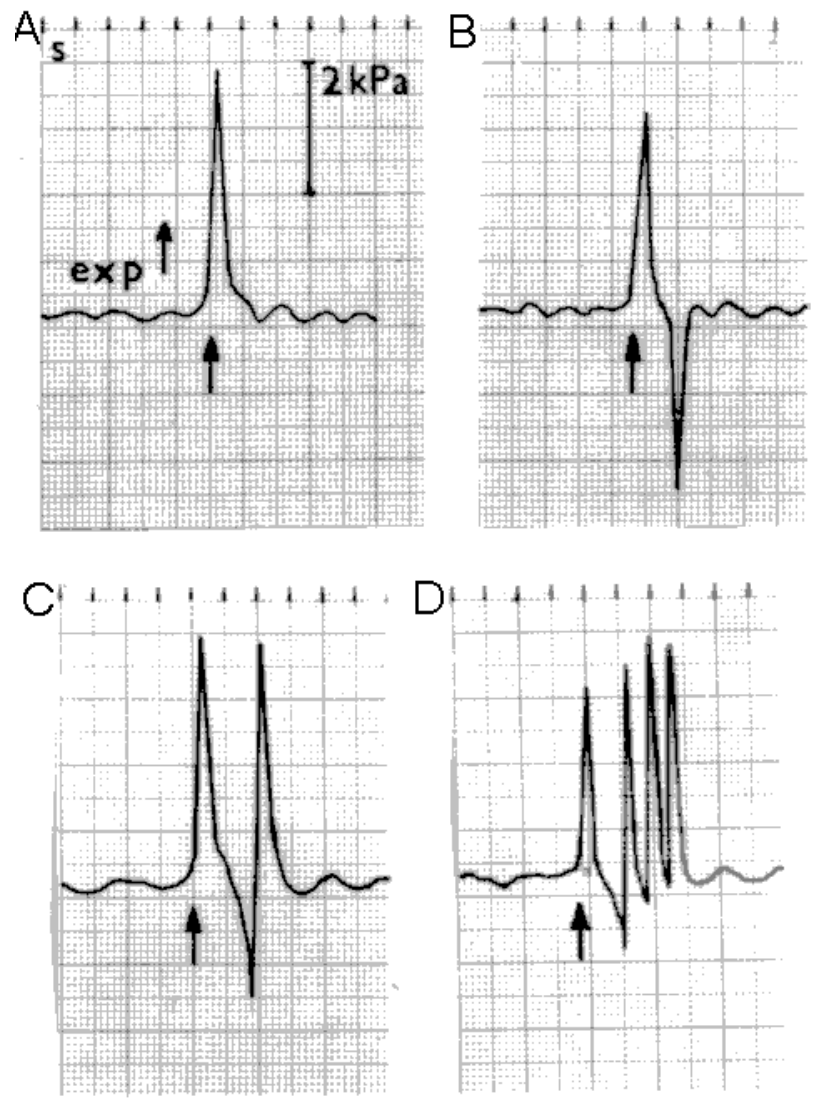

Fig. 1. Interpleural pressure recording in moment of mechanical touch ( $\uparrow$ ) of laryngeal mucous membrane

\section{Literary data on independent expiratory efforts}

After the above-mentioned finding we started our search for other literary data on the possibility of eliciting independent cough expirations. In accordance with our knowledge, Stehaelin (46) found that almost every cough effort is preceded by an inspiration when the cough stimulus is sufficiently intensive, and that its presence is not essentially required for the realisation of subsequent expiratory effort in anaesthetised 
dogs. Kandarazki (25) also recorded independent expirations between cough attacks after mechanical or electrical stimulation of the superior laryngeal nerve in anaesthetised dogs. Widdicombe (59) recorded similar single expirations which accumulated on respiratory expirations. Pressman and Kelemen (43) observed similar phenomenon, and Korpáš and Tomori (26) observed "expiratory gasping" during hypothermia in cats. Kuhn and Friebel (34) found that inspiration is not essential for the formation of cough expiratory efforts. Trendelenburg (57) described independent expiratory efforts in man after exposure to $\mathrm{SO}_{2}$. Kade and Bucher (24) and Bucher (5) observed single expiratory efforts after mechanical stimulation of laryngeal fossa in pigeons which they considered a specific expiratory activity - not cough. However, these authors did not study the principle of this phenomenon, did not pay any attention to its incidence, and did not try to explain its mechanism.

\section{Expiratory reactions in cats}

The described independent expiratory efforts were also observed in conscious cats and thus we were sure that these are not due only to anaesthesia. The strength of expiratory efforts recorded through interpleural pressure changes equalled to the strength of bronchial cough. In conscious cats the intensity of independent expiratory efforts was ten times higher than in anaesthetised animals. On the other hand, the incidence of the expiratory phenomenon followed by a subsequent cough attack was in anaesthetised animals six times more frequent than in conscious ones.

Therefore, we focused our attention on this reflex effect which we did not consider a cough, either. We decided to elaborate on this problem, and therefore started to investigate the localisation of receptive fields in larynx that could possibly produce these independent expiratory efforts. We stimulated mucosa of vocal folds and the epiglottic areas in anaesthetised cats under visual control. We found that the most effective site for evoking expiratory efforts by stimulation was medial margin of the vocal folds. This finding indicates the highest concentration of the relevant receptors. Stimulation of vocal folds was always effective when a small loop of nylon fibre was used. Among responses we often saw a double expiratory effort that we assumed a result of stimulation of two closely adjacent receptors, due to a very short refractory phase $(52,53)$.

We observed that the independent expiratory effort (Fig. 1A) was sometimes followed by a single cough effort (Fig. 1C) or by a cough attack (Fig. 1D), and, another time it was followed by a deep inspiration (Fig. 1B). The described variations were not associated with varying intensity of stimulation.

The phenomenon was elicitable not only in cats but also in other laboratory animals (rabbits, guinea-pigs, ferrets, dogs, etc.), except mice and rats (33, 55). 
In all experimental animals most effective was the stimulation of medial margin of vocal folds, less effective was that of epiglottic areas. Despite of great number of stimulations of nasal and pharyngeal mucosa we did not observe any independent expiratory efforts elicited from those sites, as described by Tomori and Stránsky (52).

While Widdicombe (60) at an early stage of the study of these phenomena considered the single expiratory effort a "cough fragment," we classified it as a defensive reflex independent from cough, not yet described in the existing literature (33).

\section{Differentiation of expiratory efforts from cough reflex}

Before this assumption could be accepted, however, it was necessary to demostrate that the expiratory efforts differ from cough reflex. Since we have learnt in our preceding studies that codeine actively inhibits cough reflex in cats, we decided to use a codeine test: repeated administration of $10 \mathrm{mg}$ of codeine per $\mathrm{kg}$ of body mass to anaesthetised cats. We found that the raising dose of codeine inhibited cough from tracheobronchial region progressively, but the independent expiratory efforts were still present. These findings were also confirmed on conscious cats. Likewise, when we progressively intensified anaesthesia (thiopental) in cats, the cough diminished but the stimulation evoked independent expiratory effort (28).

\section{The role of expiration reflex}

The described results rejected the possibility that the cough reflex and the observed expiratory reaction could be identical. In accordance with functional background of this reaction - a vigorous expiratory effort - we classified it as "expiration reflex" elicited from vocal folds (28), and we further specified the role of this reflex as "to prevent invasion of foreign bodies into airways, expelling phlegm and detritus from subglottic area, thus ensuring continual airflow through larynx indispensable for gas exchange." Accepting this, the expiratory reflex can be classified among other defensive reflexes of the airways. We have not found any mention about this reflex in the existing studies of vocal folds, either.

\section{More details about expiration reflex}

Expiratory efforts resembling expiration reflex were observed after stimulation of different parts of respiratory tract but the evidence, repeatibility and localisation were inconsistent, and thus the findings could not be regarded identical with expiration reflex (33). 
Confirmation of the essential difference between the cough reflex and expiratory reflex was most convincing after pneumotachographic studies which proved that during the expiration reflex the airflow and air volume increased, but before the effort these indexes equalled to the rate of normal respiration $(33,52)$.

In further experiments the expiratory reflex has been elicited not only by mechanical stimulation of the vocal folds but also by electrical stimulation of the superior laryngeal nerve $(7,8,16,38)$. Sullivan et al. $(48,49)$ elicited the expiratory reflex mechanically by squirting water into larynx or by a small balloon that was positioned in the rostral tracheal segment of dogs. The intranasal administration of xylene vapours elicited the expiration reflex in anaesthetised rabbits (13).

It was interesting that the described expiratory reflex was elicitable regardless of the phase of respiration which fact has been confirmed by others, too $(21,38,52,53$, 54). The best time for the elicitation was the late inspiration and early expiration which was confirmed later also by Holmer et al. (16).

The expiration reflex is superimposed on the respiratory generator and on the "cough centre" which testifies that the reflex interrupts the inspiratory and expiratory airflow or expiratory pause. When it acts together with cough attack it never merges into it but always precedes it (28, 33, 48 and others).

Our ontogenetic studies revealed that the expiration reflex occurred already in cats on the first days after birth at a time when sneezing and tracheobronchial cough were still absent (29). The results in infant rats were similar (31). The expiratory reflex was elicitable from the second day after birth although the respiratory reaction from bronchi (rats lack the cough) was present only after the 15th day of life. Stimulation of vocal folds in newborn rats and cats on the first day, in absence of the expiration reflex, often produced a reverse reaction i.e. an aspiration attack (31). This substitution with the opposite effect could be the cause of aspiration pneumonia in infants.

Sullivan et al. $(48,49)$ provided further evidence about the different feature of cough and expiratory reflex. During wakefulness the irritant laryngeal stimuli caused cough, expiratory reflex and tracheal smooth muscle constriction. During slow wave sleep or rapid eye movement sleep these responses disappeared, except the expiration reflex. Similarly, we found a different reaction in progressive isobaric hypoxia when the expiration reflex markedly diminished during the first degree of hypoxia $\left(\mathrm{FO}_{2}=0.11\right)$, whereas the laryngeal and bronchial cough were well presented till more marked hypoxia $\left(\mathrm{FO}_{2}=0.07 ; 51\right)$.

\section{Expiration reflex in pathological conditions}

Next we investigated the changes of expiratory reflex during inflammation of the vocal folds. We evoked experimental inflammation by spreading croton oil aerosol or 
turpentine oil aerosol into larynx. In croton oil inflammation the expiration reflex was unchanged. In turpentine oil inflammation the intensity of expiratory reflex decreased by about a half in consequence of histologically verified toxic effect of turpentine oil on vocal mucosa (33) which was lacking in croton oil inflammation.

Further we studied the effect of toxic and staphylococcal inflammation of the airways and in experimental pleurisy. We found that the inflammation did not alter the expiration reflex. That means that there was no analogy with the experiments in which we observed suppression of cough by inflammation (27).

In cases when due to the turpentine oil inflammation of the larynx and the vocal folds the intensity of expiration reflex was enhanced or lessened, the changes of the laryngeal cough could be the opposite. This finding allows us to assume that there are two kinds of simultaneously stimulated receptors with different sensitivity to inflammation (33).

\section{Expiration reflex in man}

It was clearly experimentally proved that the expiratory reflex in its properties differs from the cough reflex. These results naturally focused our attention on the possibility to elicit it in man. The test subjects were adult males and females. The vocal folds were stimulated mechanically using and indirect laryngoscopy after anaesthesia of the oral, pharyngeal and epiglottal mucosa induced by mesocaine aerosol (30). The reaction was evaluated on the basis of changes in oesophageal pressure, thoracogram, thermogram and phonogram. The expiratory reflex had typical features: it consisted of a single expiratory effort without the preceding inspiration, similarly as in animals (Fig. 2). The sound phenomenon was very typical with its barking sound distinct from the cough sound. The reflex could be elicited by touching the vocal folds by a nylon fibre, or a nylon loop, thin catheter, or spraying the vocal folds with distilled water (30, $39,40,42,50)$. The phenomenon of vigorous expiratory effort after touching vocal folds with some instrument (laryngoscope) or when an anaesthetic dripped on vocal folds is well known in laryngology, anaesthesiology and paediatrics but it is regarded as a cough from larynx.

That means, that the expiration reflex in man is virtually the same as in animals. Nishino et al. (39) in their studies on respiratory reflex responses in dependence on the depth of anaesthesia (enflurane), found that the most sensitive to it was the cough reflex and the most resiliant to the deepening of anaethesia was the apnoeic reflex. The other types of reflex responses, including the expiration reflex, were in between. 


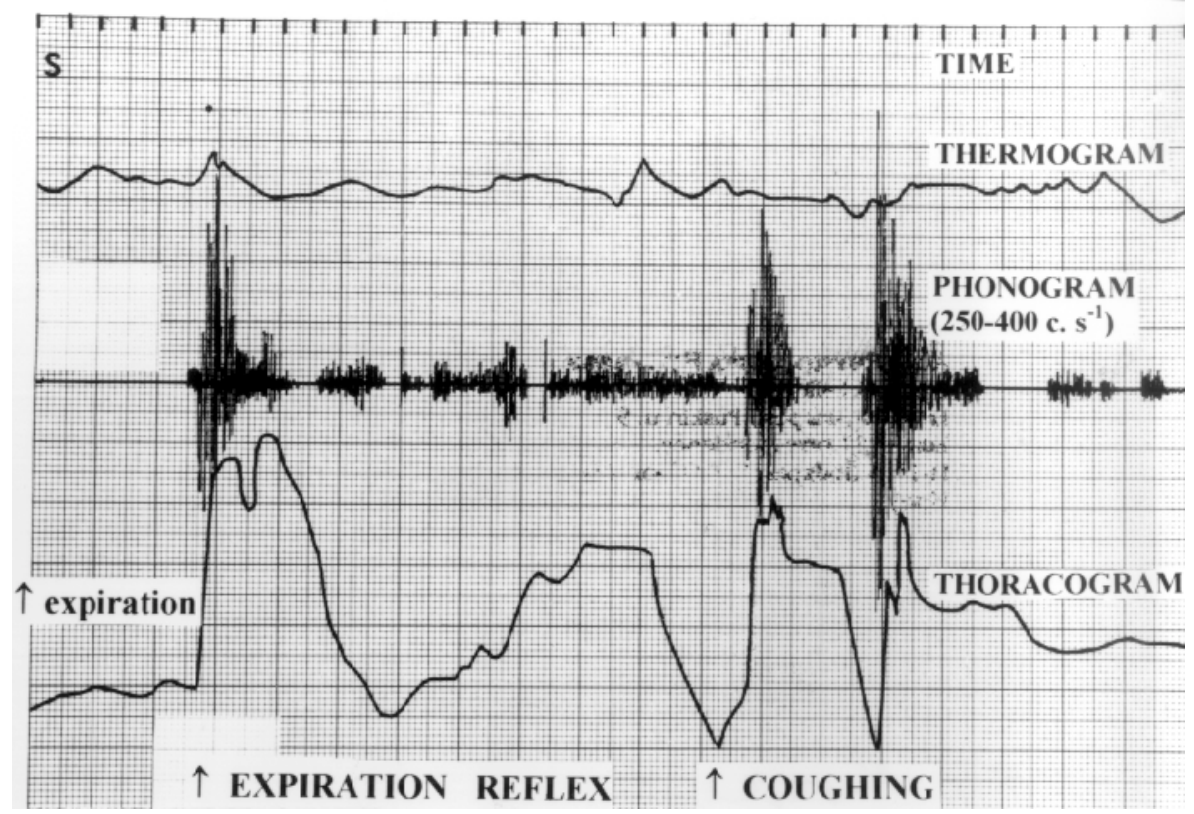

Fig. 2. Comparison of expiration reflex and coughing

An increase of $\mathrm{CO}_{2}$ ventilatory drive caused less frequent occurrence of the expiration reflex, and a decrease of $\mathrm{CO}_{2}$ ventilatory drive had the opposite effect, i.e. its frequent occurrence in spontaneously breathing female patients under enflurane anaesthesia (40). However, in anaesthetised and spontaneously breathing cats, neither changes in $\mathrm{PaCO}_{2}$ nor changes in $\mathrm{PaO}_{2}$ modify the expiration reflex produced by mechanical or electrical stimulation of the superior laryngeal nerve at different moments in the respiratory cycle (38).

In further study Nishino et al. (41) investigated the effect of lung inflation during continuous positive airway pressure (CPAP) breathing on airway defensive reflexes in enflurane anaesthetised spontaneously breathing humans. The lung inflation during CPAP does not influence either the types or duration of reflex responses to tracheal mucosa stimulation, though the intensity of the expiration reflex by inflation was augmented. The results were similar in anaesthetised rabbits and ferrets. The progressive increase of volume of the lung inflation adequately augmented the strength of the respiratory reflex $(13,58)$ in rabbits and ferrets.

The distinet nature of the compared reflexes was confirmed also in man (33). 


\section{Expiration reflex in man in pathological conditions}

In pathological conditions to elicit the reflex is easier and the effect is more marked. The vocal folds infiltrated by tumour usually reacted weakly on the impaired site and the reflex was less pronounced. In recurrent laryngeal nerve paralysis and in functional dyskinesia the reflex was not elicitable on the relevant side and it was replaced by a cough attack. It was very interesting that after vocal cordectomy the stimulation of the scar did not elicit the reflex, but after 20 days, the stimulation of the newly formed pseudo-vocal fold was effective again (32). The fact that the reproducibility of the reflex was very soon resumed (probably because neural plasticity) confirms its biological importance.

\section{The reflex arc of expiration reflex}

Various authors have described receptor endings in larynx and vocal cords by means of light microscope. Unfortunately, the observed receptors have been not correlated with their reflective function $(61,62)$. However, we did not find any report from renowned authors about the nerve endings in the vocal folds observed by electron microscopy or by immunofluorescent techniques $(6,10,15,35$ and others). Therefore, we subjected the vocal folds to an electron microscopic investigation (23). We found no nerve endings in the epithelium. Neuronal structure we did find, but only rarely and subepithelially. Since we found no other types of nerve endings, we suppose that these receptors mediate the expiration reflex. This localisation explains our experience with their stability in pathological conditions in animals and in man. Some of these receptors we also found in the supraglottal and subglottal area. According to Tomori and Stránsky (52) the receptors have the ability of rapid adaptation. We suppose that the receptors which trigger the laryngeal cough are only in laryngeal mucosa and not in the vocal folds.

For laryngeal afferentiation the superior laryngeal nerve is responsible. As assessed by single fibre recording, during stimulation of vocal folds, the frequency of the discharges rises abruptly in the superior laryngeal nerve. Its transsection results in absence of the reflex. In animals, the inferior laryngeal nerve has only additive meaning. Vice versa in man it has a primary importance. For example in patients with its paralysis, the expiration reflex is not elicitable $(32,53)$. Bilateral vagotomy in cats did not modify the expiration reflex, suggesting that the vagus has little influence on this reflex (38). On the other hand, we have stated that the inflation of lungs caused the increase in strength of the expiration reflex efforts in rabbits and ferrets $(13,58)$. 
The efferent pathway of the expiratory reflex is identical with cough and other reactions with expiratory components. That acknowledges the recording of efferent impulses in the lumbal nerve (53).

Stránsky and Tomori (47) studied the single-fibre electrical activity of the recurrent laryngeal nerve motoneurons during the expiration reflex in paralysed, pentobarbitone-anaesthetized cats. If the expiration reflex was elicited during resting inspiration, the activity of the inspiratory laryngeal motoneurone was interrupted in the compressive phase of the reflex and the expiratory laryngeal motoneurone was activated. If the expiration reflex was elicited during expiration, then bursting activity appeared in the expiratory laryngeal motoneurone during compressive phase of the reflex. No inspiratory motoneurone activity was present during the expulsive phase following stimulation.

The central nervous control of the expiration reflex is still an open problem. Thirty yeas ago we postulated that the expiration reflex is centrally represented by expiratory neurones in rhombencephalon which respond to vocal folds stimulation. However, only during the past 10-15 years our knowledge was enriched by news of respiratory neurophysiology (61).

The older findings indicated that the supposed "centre" was not identical with respiratory rhythm or the cough pattern generators. Some evidence of that was in the experience that the expiration reflex interrupts the normal respiratory rhythm $(3,7,12$, $16,18,28,36,39)$ and it is much more resistant to codeine than the cough reflex. The more recent knowledge indicates that at least a part of a neuronal network responsible for production of the expiration reflex is distinct from the cough reflex. However, we suppose a close dynamic interaction among the central pattern generators of respiratory reflexes, cough and sneezing, and vomiting which may utilise the same pools of neurones. Miller et al. (37) and Gestreau et al. (11) recently suggested the idea that multifunctional neuronal circuits exist in medulla oblongata. However, the way of interaction that may utilise the gating mechanism, probably operating in cough (2), or similarly the flexibility of neuronal reconfiguration that is triggered by an appropriate afferent inputs during the particular reflex, is unfortunately obscure.

As the cough centre is concered, a conception exists (45) that the same respiratory neuronal networks in the Bötzinger complex/rostral ventral respiratory group of the medulla oblongata produce the cough and eupnoeic breathing motor patterns. Hence, the respiratory cough pattern generators are modified in cough production by excitatory inputs from the nucleus solitarius second-order interneurone, which mediates afferent inputs from rapidly and slowly adapting receptors (44). Furthermore, the important role of modulator is supposed from the medullar dorsal and ventral respiratory groups, the rapheal, medial and lateral reticular nuclei, 
the cerebellar-interposed nuclei as well as from the pontine parabrachial nuclei, too $(11,21)$. We suppose similar central control of the expiration reflex but with different modulator inputs. Thus, the described conception may serve as a guideline in searching for the central mechanism of the expiration reflex, too.

In our former electrophysiological experiments in anaesthetised, non-paralysed cats (18), we studied electrical activity of the medullar inspiratory and expiratory ventral respiratory group neurones during the respiration, cough, sneeze and aspiration reflex. Compared to the control respiration the discharge frequency of spontaneously active expiratory neurone rises during the expiration reflex and in the expulsive phase of the cough and sneeze reflexes, whereas the inspiratory units were inversely inhibited. In addition to the former findings of Engelhorn and Weller (9) and Hanáček et al. (12), the regular recruitment of the latent units was proved not only in coughing and sneezing but also in the expiration reflex. This study clearly established that the neurones of the respiratory central pattern generator could be involved in the production of the respiratory reflex, coughing and sneezing. Furthermore, we considered the existence of anatomically precisely localised "centres" of above-mentioned reflexes within the medullar ventral respiratory group as unlikely.

The excitation in majority of reticulospinal neurones of the caudal ventral respiratory group during the expiration reflex was also noted by Bongianni et al. (3).

Ten years ago, Dyachenko (7) and Dyachenko and Preobrazhenski (8) studied the activity of medullar neurones during the expiration reflex elicited by mechanical stimulation of the vocal folds or by electrical stimulation of superior laryngeal nerve in anaesthetised cats. They found that besides the respiratory neurones a great number of non-respiratory units with reticulospinal projection were activated during the studied reflex. These critically involved units were mostly localised within the medullar gigantocellular tegmental field.

In our next study (19) we tried to locate the brainstem regions essential for the expiration and cough reflexes. For that purpose we used the method of surgical, rostral and caudal transsections at the levels of the pons and medulla oblongata. We found that successive transsection of the rostral pons toward the ponto-medullar junction area led gradually to a drop in maximal interpleural pressure values during expiration and cough reflexes. Transsection of the upper part of medulla oblongata always led to a permanent arrest of rhythmic respiration, during which the expiration and cough reflexes could not be elicited. We concluded that the central mechanisms responsible for the powerful expiratory efforts in cough and the expiration reflexes might reside in pons Varoli. 
Interesting were our medullar focal cooling studies. We explored the involvement of the rostral (intermediate) of the ventral respiratory group and the Bötzinger complex areas in generation of the expiration reflex in anaesthetised, non-paralysed cats (20). Mechanical stimulation of the vocal folds during cooling in the nucleus paraambigualis evoked only slight alterations in pleural pressure and airflow, which could not be regarded as signs related to expiration reflex. Cooling the Bötzinger complex area regularly abolished the electrophysiological and respiratory signs of the expiration reflex. Thus at the medullar level both the Bötzinger complex and the paraambigual areas (known as vital parts of the respiratory centre pattern generator) seem to be involved in production of the expiration reflex motor pattern, too. The observation is in agreement with the results of Bianchi et al. (1) who demonstrated excitatory effects of the superior laryngeal nerve stimulation on respiratory neurones found in Bötzinger complex and retrofacial nucleus. However, it cannot be excluded that cooling paraambigual nucleus may have reached some neurones in the lateral tegmental field which according to Dyachenko (7), may form the central arc of expiration reflex.

Our recent studies concerned the question whether the medullar midline raphe nuclei (21) and the neurones of the nucleus reticularis ventralis and the adjacent parts of the lateral segmental field (22) are involved in production of the motor programmes associated with the expiration and cough reflex. In order to make a functional blockade within those structures the kainic acid was microinjected (excitatory L-glutamic acid antagonist that produces functional inactivation of the cell bodies while sparing the nerve fibres) in non-paralysed anaesthetised cats. Following kainic acid injections to the raphe nuclei the mechanical stimulation of the vocal folds failed to evoke any signs of the expiration reflex in cats under chloralose the stimulation was unsuccessful in $68 \%$. Moreover, kainic acid lesions completely abolished the signs ot the tracheobronchial and laryngeal coughs. The same effects were found after kainic acid injections to the nucleus reticularis ventralis and to the surrounding lateral tegmental field ares (Fig. 3).

The similarity of results obtained from dysfunction of the midline raphe nuclei and the rostral, ventromedial part of the lateral tegmental field indicates that they both may provide an important source of facilitatory inputs either to spinal respiratory motoneurons or to the brain stem regions that could produce or mediate the expiration and cough reflexes. However, the proper role of the lateral tegmental field in production of the expiration and cough motor patterns is still not clear. We can conclude, that despite enormous efforts put in identification on brain stem regions essential for the expiration reflex, the kernel of its central regulatory mechanisms remains unknown. 


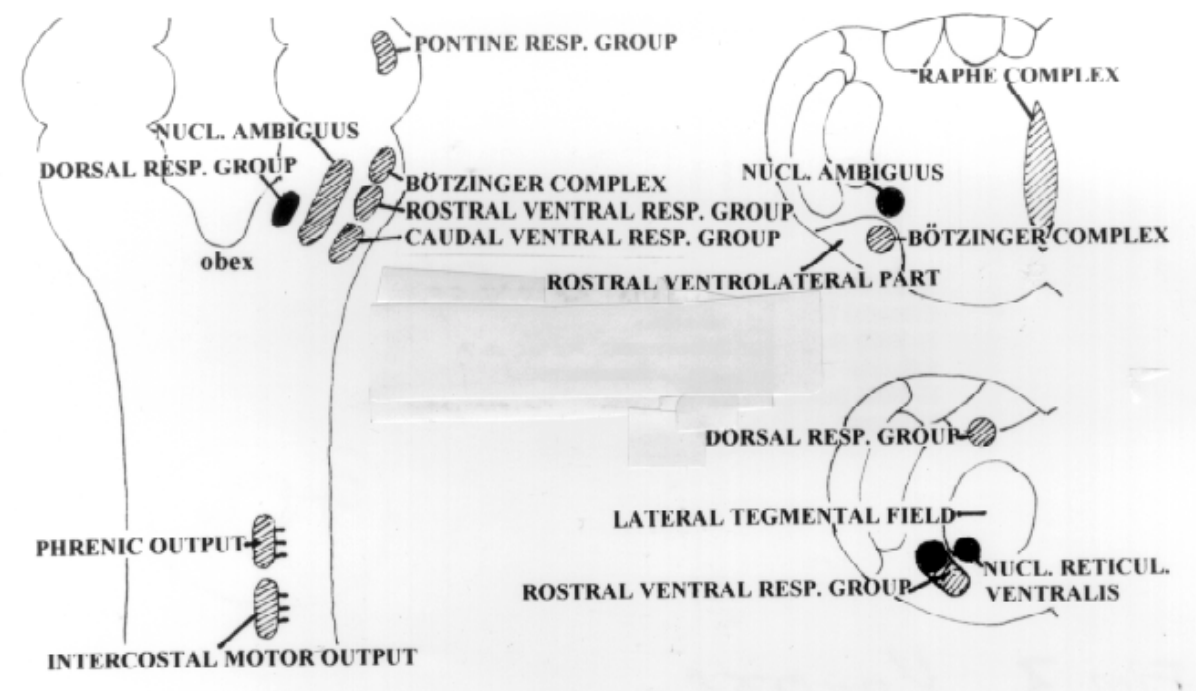

Fig. 3. Main respiratory neurone groups - schema of localization

\section{REFERENCES}

1. Bianchi, A. L., Grelot, L., Iscoe, S., Remmers, J. E.: Electrophysiological properties of rostral medullar respiratory neurones in the cat: an intracellular study. J. Physiol. (Lond.) 407, 293-310 (1988).

2. Bolser, D. C., Hey, J. A., Chapman, R. W.: Influence of central antitussive drugs on the cough motor pattern. J. Appl. Physiol. 86, 1017-1024 (1999).

3. Bongianni, F., Corda, M., Fontana, G., Paantaleo, T.: Electrophysiological properties of rostral medullar respiratory neurones in the cat: an intracellular study. J. Appl. Physiol. 65, 385-392 (1988).

4. Bucher, K., Jacot, C.: Zum mechanismus des Hustens. Helv. Physiol. pharmacol. Acta 9, 454-462 (1951).

5. Bucher, K.: Respiratory changes following reflexogenic expiratory twitches. Agents. Action 3, 61-65 (1973).

6. During, M., Andres, K., H.: Structure and functional anatomy of visceroreceptors in mammalian respiratory system. pp. 139-154. In: Progress in Brain Research, eds Hamann, W., Iggo, A., Elsevier Science Publishers, Amsterdam 1988.

7. Dyachenko, Y.: The participation of bulbar "respiratory" and "nonrespiratory" neurones in the development of the expiration reflex (Russian). Neirofiziologija 22, 670-680 (1990).

8. Dyachenko, Y. A., Preobrazhenskij, N. N.: Responses of bulbo-spinal neurones during expiration reflex in cats (Russian). Neirofiziologija 23, 88-98 (1991). 
9. Engelhorn, R., Weller, E.: Zentrale Repräsentation hustenwirksamer Afferenzen in der Medulla oblongata der Katze. Pflugers Arch. ges. Physiol. 284, 224-239 (1965).

10. Fillentz, M., Widdicombe, J. G.: Receptors of the lung and airways. pp. 81-112. In: Handbook of Sensory Physiology, Vol. 3, ed. Antrum, H., Springer Verlag, Berlin 1971, and p. 233.

11. Gestreau, C., Bianchi, A. L., Grélot, L.: Differential brainstem FOS-like immunoreactivity after laryngeal induced coughing and its reductions by codeine. J. Neurosci. 17, 9340-9352 (1997).

12. Hanácek, J., Korpáš, J., Kulik, A. M., Kondrateva, L. N.: Changes of electrical activity in the respiratory centre during the expiration reflex. Physiol. Bohemoslov. 26, 253-256 (1977).

13. Hanácek, J., Korpáš, J.: Modification of the intensity of the expiration reflex during short-term inflation of the lungs in rabbits. Physiol. Bohemoslov. 31, 159-174 (1982).

14. Hanácek, J., Davies, A., Widdicombe, J. G.: Influence of lung stretch receptors on the cough reflex in rabbits. Respiration 45, 161-168 (1984).

15. Hayek, H.: Die menschliche Lunge. Springer Verlag, Berlin-Heidelberg-New York 1970, p. 379.

16. Holmer, B. H., Marek, W., Scheid, P.: Der Einfluss laryngealer Afferenzen auf inspiratorische und exspiratorische Nerven und Muskeln der Katze. Atemw. - Lungenkrkh. 12, 327-332 (1986).

17. Ivančo, I., Korpáš, J.: K otázke laryngeálneho a tracheálneho kaš’a (in Slovak). Bratisl. Lek. Listy 34, 1391-1396 (1954).

18. Jakuš, J., Tomori, Z., Stránsky, A.: Activity of bulbar respiratory neurones during cough and the respiratory tract reflexes in cats. Physiol. Bohemoslov. 34, 127-136 (1985).

19. Jakuš, J., Tomori, Z., Boše'ová, L', Nagyová, B., Kubinec, V.: Respiration and airway reflexes after transversal brain stem lesions in cats. Physiol. Bohemoslov. 36, 329-340 (1987).

20. Jakuš, J., Stránsky, A., Poliaček, I., Baráni, H.: Laryngeal patency and expiration reflex following focal cold block of the medulla in cat. Physiol. Res. 45, 107-116 (1996).

21. Jakuš, J., Stránsky, A., Poliaček, I., Barányi, H., Bošel'ová, L.: Effects of medullary midline lesions on cough and other airway reflexes in anaesthetised cats. Physiol. Res. 47, 203-213 (1998).

22. Jakuš, J., Stránsky, A., Poliaček, I., Bárányi, H., Bošel'ová, L'.: Kainic acid lesions to the lateral tegmental field of medulla: effect on cough, expiration and aspiration reflexes in anaesthetised cats. Physiol. Res. 49, 387-398 (2000).

23. Jeffery, P. K., Korpáš, J., Widdicombe, J. G.: Intraepithelial nerve fibres of the cat larynx and the expiration reflex. J. Physiol. (Lond.) 275, 35P-36P (1978).

24. Kade, F., Bucher, K.: Charakteristik der exspiratorischer Anfalle bei der Traube. Helv. Physiol. Acta 25, 241-248 (1967)

25. Kandarazki, M.: Ueber den Husten nebst einigen Bemerkungen ueber den Einfluss des Chloroforms auf die Atmung der Tiere. Pflugers Arch. ges. Physiol. 26, 470-479 (1881).

26. Korpáš, J., Tomori, Z.: Über den Einfluss der Hypothermie auf den Husten und die Atmung. Physiol. Bohemoslov. 4, 487-493 (1957).

27. Korpáš, J., Bilcík, P., Fraenkel, E.: Changes in coughing in cats with experimental or spontaneous inflammation of the respiratory tract. Physiol. Bohemoslov. 14, 488-494 (1965).

28. Korpáš, J.: Differentiation of the expiration and cough reflex. Physiol. Bohemoslov. 21, 677-680 (1972).

29. Korpáš, J., Kalocsayová, G.: Mechanoreception of the cat respiratory tract on the first days of the postnatal life. Physiol. Bohemoslov. 22, 365-373 (1973)

30. Korpáš, J., Mišík, A., Kalocsayová, G.: The expiration reflex in man. Physiol. Bohemoslov. 24, 253-256 (1975).

31. Korpáš, J., Tatár, M.: The expiration reflex during ontogenesis in the rat. Physiol. Bohemoslov. 24, 257-261 (1975).

32. Korpáš, J., Mišík, A., Kalocsayová, G.: The expiration reflex during pathological conditions in man. Bull. Physiopath.Resp. 11, 107P-109P (1975).

33. Korpáš, J., Tomori, Z.: Cough and other respiratory reflexes. S. Karger, Basel-Munchen-ParisLondon-New York-Sydney 1979, p. 368. 
34. Kuhn, H. N., Friebel, H.: Zur Einordnung des Hustenstosses in den Atemrhythmus. Med. exp. 3, 329-335 (1960).

35. Laitinen, A.: Ultrastructural organisation of intraepithelial nerves in the human airway tract. Thorax 40, 488-492 (1985)

36. Lawson, E. E., Richter, D. W., Czyzyk-Krzeska, M., Bischoff, A., Rude-Sill, R. G.: Respiratory neuronal activity during apnoe and other breathing patterns induced by laryngeal stimulation. J. Appl. Physiol. 70, 2742-2749 (1991).

37. Miller, A. D., Monaka, S., Siniaia, M. S., Jakuš, J.: Multifunctional ventral respiratory group: bulbospinal expiratory neurones play a role in pudendal discharge during vomiting. J. Autom. Nerv. system 54, 253-260 (1995).

38. Nishino, T., Honda, Y.: Time dependent responses of expiration reflex in cats. J. Appl. Physiol. 61, 430-435 (1986).

39. Nishino, T., Hiraga, K., Miyuguchi, T., Honda, Y.: Respiratory reflex responses to stimulation of tracheal mucosa in enflurane-anaesthetised humans. J. Appl. Physiol. 65, 1069-1074 (1988).

40. Nishino, T., Hiraga, K., Honda, Y.: Inhibitory effects of $\mathrm{CO}_{2}$ on airways defensive reflexes in enflurane anaesthetised humans. J. Appl. Physiol. 66, 2643-2646 (1989).

41. Nishino, T., Sugimori, K., Hiraga, K., Honda, Y.: Influence of CPAP on reflex responses to tracheal irritation in anaesthetised humans. J. Appl. Physiol. 67, 954-958 (1989).

42. Nishino, T., Tagaito, Y., Issono, S.: Cough and other reflexes on irritation of airway mucosa in man. Pulm. Pharmacol. 9, 285-292 (1996).

43. Pressman, J.J., Kelemen, G.: Physiology of the larynx. Physiol. Rev. 35, 506-554 (1955).

44. Shannon, R., Bolser, D. C., Lindsey, B. G.: Neural control of coughing and sneezing. pp. 213-222. In: Neural Control of Respiratory Muscles, eds Miller, A. D., Bianchi, A. L., Bishop, B. P., CRC, Boca Raton 1997.

45. Shannon, R., Baekey, D. M., Kendall, F. M., Lindsey, B. G.: Ventrolateral medullary respiratory network and a model of cough motor pattern generation. J. Appl. Physiol. 84, 2020-2035 (1998).

46. Stehaelin, R.: Respirationskrankheiten. Jahreskurse ärztl. Forb. 5, 32-43 (1914).

47. Stránsky, A., Tomori, Z.: Changes in laryngeal motoneurone activity and in laryngeal calibre during the expiration reflex. Physiol. Bohemoslov. 28, 365-373 (1979).

48. Sullivan, C. E., Murphy, E., Kozar, L. F., Phillipson, E. A.: Waking and ventilatory responses to laryngeal stimulation in sleeping dogs. J. Appl. Physiol. 45, 681-689 (1978).

49. Sullivan, C. E., Kozar, L. F., Murphy, E., Phillipson, E. A.: Arousal, ventilatory and airway responses to bronchopulmonary stimulation in sleeping dogs. J. Appl. Physiol. 47, 17-25 (1979).

50. Tagaito, Y., Isono, S., Nishino, T.: Upper airway reflex during a combination of proposal and fentanyl anaesthesia. Anaesthesiology 88, 1459-1466 (1998).

51. Tatár, M., Korpáš, J., Polacek, H., Záhradný, V.: Changes induced by severe hypoxia in respiratory defence reflexes in anaesthetised cats. Respir. 49, 114-121 (1986).

52. Tomori, Z., Stránsky, A.: Electroneurographic and pneumotachographic analysis of the expiration reflex. Physiol. Bohemoslov. 22, 589-601 (1973).

53. Tomori, Z., Stránsky, A.: Mechanisms of the expiration reflex. Bull. Physiopathol. Resp. 9, 1281 (1973).

54. Tomori, Z., Lemáková, S., Gromysz, H., Stránsky, A.: Changes in the respiratory centre activity elicited by mechanical stimulation of the airways. Bull. Physiopathol. Resp. 12, 76P-78P (1976).

55. Tomori, Z., Lemáková, S., Holéczyová, A.: Defensive reflexes of the respiratory tract in dogs. Physiol. Bohemoslov. 26, 49-54 (1977)

56. Tomori, Z., Lemáková, S., Gromysz, H., Stránsky, A.: Changes in the respiratory centre activity elicited by mechanical stimulation of the airways. pp. 129-138. In : Respiratory centres and afferent systems, ed. Duron, B., INSERM, Paris 1976, p. 354.

57. Trendelenburg, U.: Über die wirkung einiger Hustenmittel auf Hustenreizschwele und Atmung. Acta physiol. scand. 21, 174-186 (1950). 
58. Turčan, J., Korpáš, J., Hanácek, J.: The effect of short-term lung inflation upon the expiration reflex intensity under normal and pathological conditions in ferrets. Physiol. Bohemoslov. 80, 53-59 (1983).

59. Widdicombe, J. G.: Respiratory reflexes from the trachea and bronchi of the cat. J. Physiol. (Lond.) 123, 55-70 (1954).

60. Widdicombe, J. G.: Laryngeal and tracheal reflexes. pp. 279-282. In : Respiratory Physiology. Vol. 2. ed. Widdicombe, J. G., University Park Press, London-Baltimore 1974, p. 381.

61. Widdicombe, J. G.: Neurophysiology of the cough reflex. Eur. Resp. J. 8, 1193-1202 (1995).

62. Widdicombe, J. G.: Afferent receptors in the airways and cough. Resp. Physiol. 114, 5-15 (1998). 